\title{
Design and Implementation of an IMC-1DOF Controller Applied to MPPT Photovoltaic Systems Using ZVS Full-Bridge DC-DC Converter
}

\author{
E. N. Chaves ${ }^{1}$, G. P. Viajante ${ }^{1}$, M. A.A. de Freitas ${ }^{1}$, E. A. A. Coelho ${ }^{2}$, M.E Oliveira ${ }^{1}$, R. Nielson ${ }^{3}$, \\ L.G Wesz ${ }^{1}$ and G. Moraes ${ }^{2}$ \\ ${ }^{1}$ Instituto Federal de Educação, Ciência e Tecnologia de Goiás, Itumbiara - GO, Brasil \\ e-mail: eric.neryx@gmail.com, ghunterp@gmail.com
}

${ }^{2}$ Universidade Federal de Uberlândia, Uberlândia - MG, Brasil

e-mail: ernane@ufu.br

${ }^{3}$ Enel Distribuição Goiás

\begin{abstract}
This paper presents the design of an Internal Model Control - 1 Degree of Freedom (IMC-1DOF) controller applied to a Zero Voltage Switching (ZVS) Full-Bridge DC-DC converter that will be used in photovoltaic systems for Maximum Power Point Tracking (MPPT), with the objective of developing a single phase micro inverter. It will be presented the mathematical modeling of this converter to control the input voltage aiming the application in MPPT and the design of the respective controller IMC-1DOF. The proposal testing and validation strategy was performed by comparison with a PI compensator. The performance of both controllers are evaluated and discussed.
\end{abstract}

Keywords. Internal Model Control, ZVS Full-Bridge Converter, Photovoltaic Generation, MPPT, Maximum Power Point Tracking.

\section{Introduction}

Several commercial inverters work with strings, which are series and / or parallel arrays of photovoltaic panels at their inputs and have a DC-DC converter - usually a Boost - per string for the purpose of tracking the maximum power point (MPPT). However, when partial shading of one or more PV panels of a string occurs, part of the energy generated is lost because the overall maximum point (in terms of generated power) is not the algebraic sum of local maximums that occur in shading cases, thus reducing the overall efficiency of these systems. In order to overcome this limitation, [1] proposed the topology in which each PV panel or even a small string has its own DC-DC converter that is connected to a single centralized DC-AC converter.

For the purpose of increasing the economic feasibility and the flexibility in terms of installed power, added to the efficiency increase when using a converter for each PV panel, the integrated micro-inverters were proposed, which add MPPT functionalities and connection to the AC grid [2].
A DC-DC converter typically used in this application is ZVS Full-Bridge, because the static gain can be easily achieved in the proper design of its transformer.

In addition, the zero voltage switching (ZVS) obtained by PWM by phase shift modulation makes this converter energy efficient due to the consequent reduction of conduction losses in the switches, which is the expected in PV systems [3].

In [4] a study of this converter is presented, in the composition of a micro inverter, however, more attention was given to the study of the dynamics of the inverter output LCL filter and the control of the current injection made by the resonant controller. Whereas in [5] a detailed study of the dynamics of the ZVS Full-Bridge converter is made and its model of small signals for application in MPPT is presented. However, the design of suitable compensators for this converter and application has not been addressed.

Therefore, the objective of this paper is to present the design of an IMC-1DOF controller applied to a ZVS Full-Bridge DC-DC converter that will be used in photovoltaic systems maximum power point tracking, with a view to developing a micro inverter integrated in the module (MIC) in connection with the single phase mains. It will be presented the mathematical modeling of this converter, for the control of its input voltage, aiming the application in MPPT, and the design of the respective controller IMC-1DOF

Aiming to validate the control strategy a PI compensator will also be designed and computational simulation results will be shown in which the performance of both controllers are evaluated. The performance is evaluated in terms of transient and steady state response and against sudden variations in the reference voltage (produced by the $\mathrm{P} \& \mathrm{O}$ algorithm) and in the irradiance that feeds the photovoltaic array model.

Figure 1 shows the system structure involving the MPPT (Disturb and Observe - P\&O) and the IMC controller, both in conjunction with the ZVS Full-Bridge DC-DC converter. 


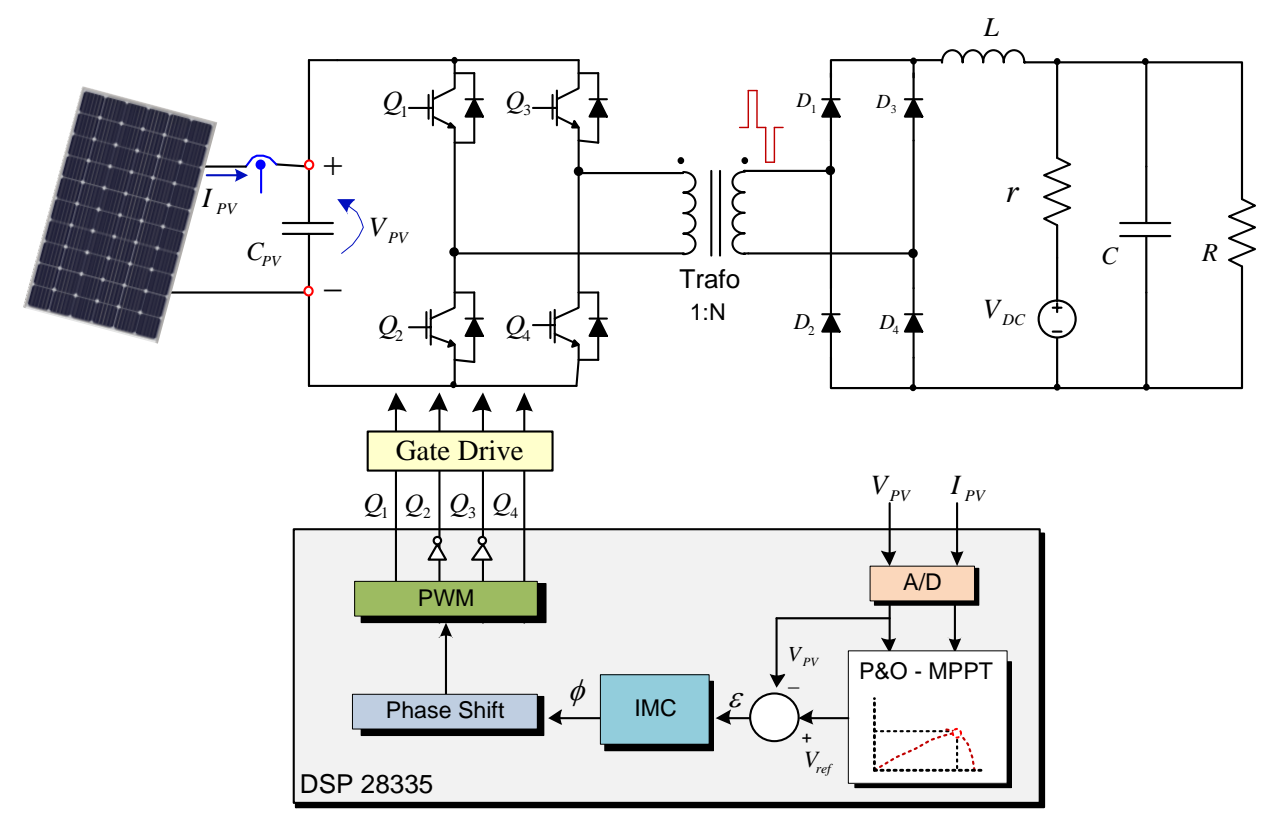

Fig. 1. System structure involving MPPT, IMC controller and ZVS Full-Bridge DC-DC converter

\section{Aspects of ZVS Full-Bridge Converter for Input Voltage Control}

\section{A. DC-DC Converter Modeling}

For the controller design, the modeling process of the ZVS Full-Bridge CC-DC converter was performed through medium state spaces. This modeling was first presented in [6], and was developed as a technique for obtaining a model of mean variables in the state space, resulting in a linear model valid for small perturbations by linearization around an operation point.

For mathematical modeling, the ideal voltage source in series with a small resistance (r) (Figure 1) was replaced by the circuit of Figure 2 in which the output is represented by a load resistance $(\mathrm{R})$ in parallel with the capacitor. of the voltage filter (C).

This aims to obtain the linear model of the system for the worst case where, on the one hand, the DC bus would not behave as an ideal source due to voltage ripple caused by a future single-phase connection of this system into the grid and, on the other hand, issues involving a possible LC resonance. The idea is that from this mathematical model and the correct design of the compensators, gains that could lead the system to instability in the resonant frequency of the output LC circuit would be avoided.

However, for computer simulations the output was again represented by a load and a DC voltage source. The load is required to absorb the output power of the DC-DC converter and the source to represent the bus and allow: a) MPPT to occur over the entire length of the IxV curve of the photovoltaic array and, b) the voltage variation of input from modulation to PWM wave cycle active composition.

In this way, for a single half-cycle of the AC signal at the transformer primary, two steps associated with the converter were considered. During Step 1, shown in Figure 2 (a), switches $Q_{2}, Q_{3}, D_{1}$ and $D_{4}$ remain closed for a time dTSW and $Q_{1}, Q_{4}, D_{2}$ and $D_{3}$ open. In Step 2, Figure 2 (b), switches $D_{2}$ and $D_{4}$ remain freewheeled to the inductor current (L) for a time equivalent to (1-d) $\mathrm{T}_{\mathrm{SW}}$. In addition, switches $Q_{1}$ and $Q_{3}$ or $Q_{2}$ and $Q_{4}$ also remain closed on (1-d) $T_{S W}$ by shorting the transformer primary terminals and thus creating the zero voltage level required by the ZVS method [5].

For this mathematical modeling, we chose to neglect the transformer inductances, taking into account only its transformation relationship $\left(N_{1}: N_{2}\right)$. This choice was due to the fact that the inductance $(\mathrm{L})$ is much larger than the transformer dispersion inductances and therefore dominates the dynamics of this converter.

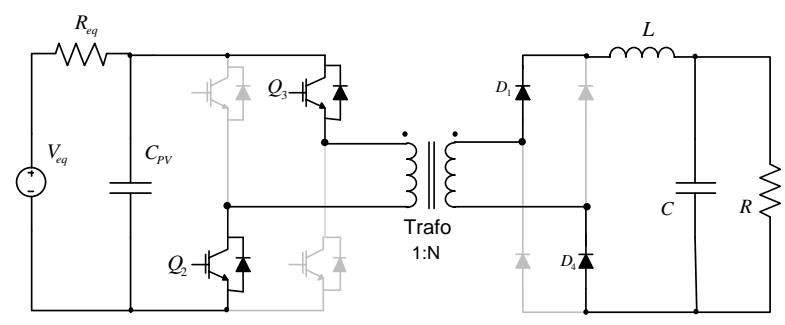

(a)

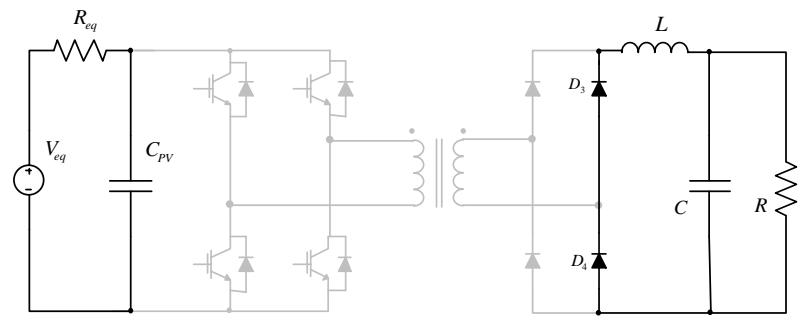

(b)

Fig. 2. DC-DC converter steps at both switching intervals.

In addition, even the DC bus voltage being controlled by the DC-AC current injection into the grid (typical case in a MIC in connection with the grid), which would make 
it simplified to consider the DC bus as a source with independent DC voltage, it was decided to consider the bus capacitor $(\mathrm{C})$ in parallel with a load $(\mathrm{R})$ and this, in turn, capable of absorbing all the energy generated in the photovoltaic arrangement.

Thus, the converter can be described by linear state equations as:

$$
\begin{aligned}
& \dot{x}=A_{1} x(t)+B_{1} u(t) \\
& \dot{x}=A_{2} x(t)+B_{2} u(t)
\end{aligned}
$$

where:

$$
x=\left[\begin{array}{c}
v_{p v} \\
i_{L} \\
v_{C}
\end{array}\right] \quad \text { e } \quad u(t)=V_{e q} .
$$

The dynamic matrices for each operation step are given respectively by:

$$
A_{1}=\left[\begin{array}{ccc}
\frac{-1}{C_{p v} R_{e q}} & \frac{-N_{2}}{N_{1} C_{p v}} & 0 \\
\frac{N_{2}}{N_{1} L} & 0 & \frac{-1}{L} \\
0 & \frac{1}{C} & \frac{-1}{R C}
\end{array}\right]
$$

and

$$
A_{2}=\left[\begin{array}{ccc}
\frac{-1}{C_{p v} R_{e q}} & 0 & 0 \\
0 & 0 & \frac{-1}{L} \\
0 & \frac{1}{C} & \frac{-1}{R C}
\end{array}\right] .
$$

The coupling matrices with the input for each operating step are given respectively by:

$$
B_{1}=B_{2}=\left[\begin{array}{c}
1 / C_{p v} R \\
0 \\
0
\end{array}\right]
$$

Considering that converter operates in continuous driving mode (MCC), the dynamic and input matrices can be represented by their average values::

$$
A_{\text {med }}=A_{1} D+A_{2}(1-D) \text { e } B_{\text {med }}=B_{1} D+B_{2}(1-D) .
$$

To perform the linearization, the steady state operating point must be obtained, where the derivatives of the state variables will become null. Thus, the average values of the state variables are:

$$
X_{\text {med }}=\left[\begin{array}{c}
V_{P V} \\
I_{L} \\
V_{C}
\end{array}\right] .
$$

thus in[18]:

$$
B_{d}=\left[A_{1}-A_{2}\right] X_{\text {med }}+\left[B_{1}-B_{2}\right] V_{e q}
$$

applying the small signal model to the mean state space equation and simplifying it, and then applying the Laplace Transform to the equation, results in:

$$
\hat{X}(s)=\left(s I-A_{\text {med }}\right)^{-1}\left[B_{\text {med }} \hat{U}(s)+B_{d} \hat{D}(s)\right] .
$$

Therefore, the transfer functions of state variable perturbations in relation to perturbations in cyclic ratio $\mathrm{D}$ will result in:

$$
G_{x d}(s)=\frac{\hat{X}(s)}{\hat{D}(s)}=\left(s I-A_{\text {med }}\right)^{-1} B_{d} .
$$

Since you want to control the input voltage of the ZVS Full-Bridge converter in order to extract maximum power from the PV array, the transfer function can be written as:

$$
\hat{G}_{v_{p v}} / d=\frac{N_{2} R_{e q}\left(b_{2} s^{2}+b_{1} s+b_{0}\right)}{a_{3} s^{3}+a_{2} s^{2}+a_{1} s+a_{0}}
$$

in which:

$$
\begin{gathered}
b_{0}=D N_{2} V_{P V}+I_{L} N_{1} R \\
b_{1}=I_{L} L N_{1}+C D N_{2} R V_{P V} \\
b_{2}=C I_{L} L N_{1} R \\
a_{0}=N_{1}^{2} R+D^{2} N_{2}^{2} R_{e q} \\
a_{1}=L N_{1}^{2}+C_{p v} N_{1}^{2} R R_{e q}+C D^{2} N_{2}^{2} R R_{e q} \\
a_{2}=C L N_{1}^{2} R+C_{p v} L N_{1}^{2} R_{e q} \\
a_{3}=C C_{p v} L N_{1}^{2} R R_{e q}
\end{gathered}
$$

\section{B. Phase Shift PWM}

The switching is performed by the PWM technique via phase shift (Phase Shift PWM) in which two comparators are used (one for each branch of the Full-Bridge inverter) keeping the modulating signal fixed for both comparators and the carrier triangular waveform in one of the comparators. The active cycle or pulse width $(D)$ is obtained by shifting the carrier phase (also triangular) of the second comparator in the other branch of the inverter. In this way zero voltage switching $(Z V S)$ is obtained and the operation of the converter can be grouped into a single half-cycle of the AC signal on the transformer primary.

The scheme used in the simulation for phase shift PWM modulation in the PSIM ${ }^{\circledR}$ software environment is shown in Figure 3.

It is possible to see in Figure 3 the comparators with the same modulating signal, in this case zero volts at the non-inverting input so as to be fixed at the mean value of the triangular carriers that increase from -1 to $1 \mathrm{~V}$. The figure also shows the fixed phase triangular carrier and the switching frequency of the DC-DC converter at the inverter input of the upper comparator responsible for switching the left branch of the inverter (switches $Q_{1}$ and 
$Q_{2}$ ). Thus, the arrangement for obtaining the triangular wave that arrives at the inverter input of the lower comparator and is responsible for switching the right branch of the inverter (switches $Q_{2}$ and $Q_{3}$ ).

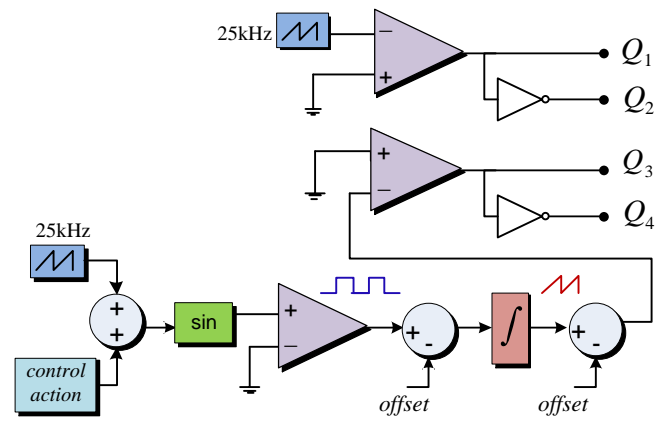

Fig. 3. Phase shift PWM modulation structure

\section{ZVS Full-Bridge Converter Specifications}

The ZVS Full-Bridge converter is designed to track the maximum power of a photovoltaic array and raise the voltage to $350 \mathrm{VDC}$. The design of this DC-DC converter is described in [7]. However, the parameters used for the DC-DC converter are shown in Table I.

Table I - ZVS Full-Bridge Parameters

\begin{tabular}{|l|c|c|}
\hline \multicolumn{1}{|c|}{ Parameters } & Name & Value \\
\hline Input Capacitance & $C_{p v}$ & $220 \mu \mathrm{F}$ \\
\hline Output Capacitance & $C$ & $2200 \mu \mathrm{F}$ \\
\hline Filter Inductance & $L$ & $4,0 \mathrm{mH}$ \\
\hline DC Bus Voltage & $V_{C}$ & $350 \mathrm{~V}$ \\
\hline Cyclic reason & $D$ & $30 \%$ \\
\hline Switching Frequency & $f_{S}$ & $60 \mathrm{kHz}$ \\
\hline Equivalent Voltage & $V_{e q}$ & $80 \mathrm{~V}$ \\
\hline Equivalent Resistance & $R_{e q}$ & $5 \Omega$ \\
\hline Average Input Voltage & $V_{P V}$ & $35 \mathrm{~V}$ \\
\hline Inductor Average Current & $I_{L}$ & $1 \mathrm{~A}$ \\
\hline Number of Primary Turns & $N_{I}$ & 1 \\
\hline Number of Secondary Turns & $N_{2}$ & 5 \\
\hline
\end{tabular}

\section{PI Compensator Design}

The PI compensator was designed with the aid of the Sisotool® tool from Matlab® software. Tuning was done using the Ziegler-Nichols method for unit step response. The transfer function of this compensator is:

$$
G_{P I}(s)=0,013278 \frac{(s+1822)}{s}
$$

Figure 4 shows the Sisotool ${ }^{\circledR}$ tool screen. It is possible to see the bode diagrams for open loop gain, root geometry, system response to unit step (system already compensated) and compensator tuning screen. There was an overshoot of $42.5 \%$ with a very oscillatory response. In addition, the accommodation time of 0.0378 s allows $\mathrm{P} \& \mathrm{O}$ to have a refresh rate (VREF) of up to $25 \mathrm{~Hz}$.

An exhaustive fine-tuning of this PI compensator has been made to obtain the least oscillatory response possible.
The best result was obtained by applying a gain of 0.001 to the compensator output defined in equation (20).

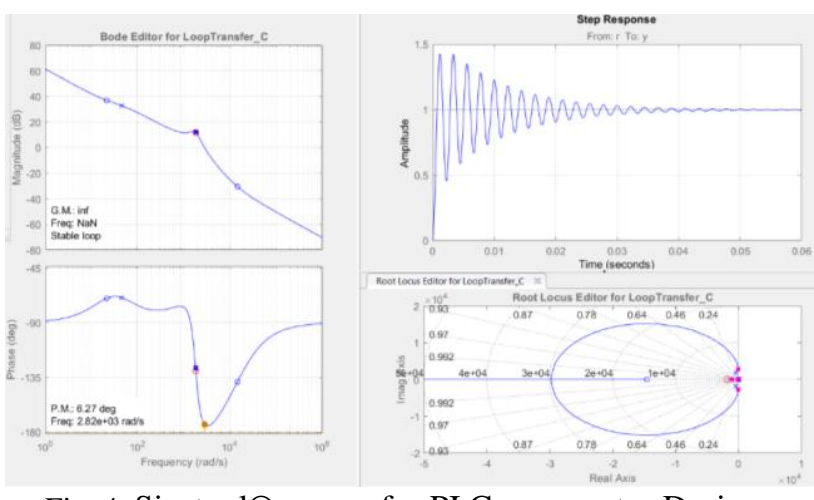

Fig. 4. Sisotool@ screen for PI Compensator Design

\section{Internal Model Compensator Design}

Figure 5 shows the generic form of an internal model-based control strategy with one degree of freedom - IMC 1DOF, where $p(s)$ is the process, $\tilde{p}(s)$ is the process model, $u(s)$ is the control effort.,$d(s)$ is the perturbation and $\tilde{d}_{e}(s)$ is the estimated perturbation [8].

Since model $\tilde{p}(s)$ is a perfect representation of a stable process $p(s)$, if the controller gain $q(s, \varepsilon)$ is the inverse of the model gain, then the process output $y(s)$ will eventually reach and maintain reference $r(s)$ as long as the process gain and model gain have the same signal, and the controller is tuned to ensure stability.

For a single input, single output (SISO) system the model is a linear transfer function and the controller is the approximate inverse of the transfer function of this model.

The purpose of this strategy can be defined as:

$$
y(s)=r(s) \text { and } y(s) / d(s)=0
$$

since:

$$
p(s) q(s)=1 \quad \text { and } \quad \tilde{p}(s)=p(s) .
$$

Therefore, for the control action to be effective in tracking the reference, a perfect model is required, and from equations (21), the controller must perfectly invert this model [8].

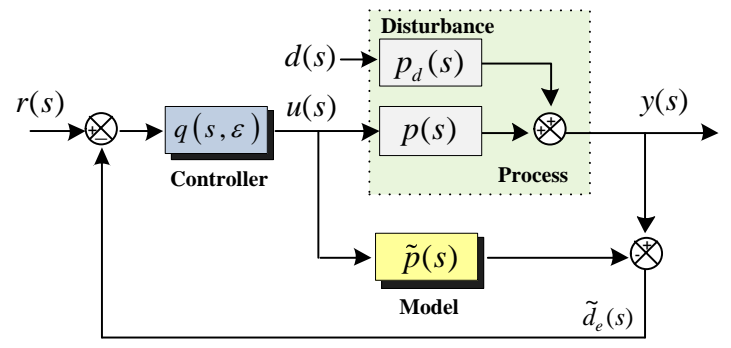

Fig. 5. Control structure based on IMC 1 DOF.

\section{A. IMC-1 DOF Controller Design}

Using the criteria discussed in [8], for the design of these controllers, when the process transfer function has no zeros close to the imaginary axis nor in the right half plane of the $s$ plane, the IMC 1DOF controller can be designed as: 


$$
q(s)=\frac{D(s)}{N(s) \cdot(\varepsilon s+1)^{r}}
$$

where: $N(s)$ is the numerator polynomial and $D(s)$ is the transfer function denominator polynomial, already described in (12) and corresponding to the process $p(s)=$ $\hat{G}_{v_{p v} / d}$, and $r$ is defined as the difference between the denominator order minus the numerator order of the transfer function.

Expression (24) has the filter term that makes $q(s)$ causal and therefore physically achievable, where $\varepsilon$ is a parameter that defines the cutoff frequency of this filter.

$$
\frac{1}{(\varepsilon s+1)^{r}}
$$

For the IMC 1DOF controller design, the filter term $\varepsilon$ defined in (24) can be calculated by (25) where the maximum gain allowed at high frequency is arbitrated at 20 times the gain at low frequency [8].

$$
\varepsilon \geq\left(\lim _{s \rightarrow \infty} \frac{D(s) N(0)}{20 s^{r} N(s) D(0)}\right)^{1 / r}
$$

However, better results were obtained by keeping the value of $\varepsilon$ at 0.00017 .

\section{Simulations Results}

The $\mathrm{P} \& \mathrm{O}$ algorithm reads the instantaneous voltage and current values and then calculates the instantaneous power. Thus the algorithm compares the previous power with the current power and, after this comparison, updates $V_{\text {Ref }}$ to track the maximum power. The algorithm disturbs the reference voltage allowing the controllers to act on $V_{P V}$ to modify the voltage at the panel terminals.

For the simulations a $1 \mathrm{~V}$ step of reference voltage disturbance was used. The panel association voltage and current sampling frequency was determined as a function of the time of the response of the controllers, thus having an update frequency $f_{m p p t}=100 \mathrm{~Hz}$.

\section{A. Results for the PI compensator}

Figure 6 shows the result of the simulation of maximum power tracking when the panel model is subjected to different light and temperature patterns. The overlapping dashes indicate the power generated by the panels (in the subtitle, Panel) and the power (in the subtitle, $P_{p v}$ ) extracted from the panels and delivered to the load as a result of the $\mathrm{P} \& \mathrm{O}$ algorithm added to the action of the PI compensator in the internal variable control loop. $V_{P V}$.]

Figure 7 shows the reference voltage $\left(V_{R e f}\right)$ being disturbed by $\mathrm{P} \& \mathrm{O}$, the different levels (coincident with the maximum power points - MPPs) around which this voltage stabilizes (although it continues to be disturbed by $\mathrm{P} \& \mathrm{O}$ ) and the voltage in $V_{P V}$ photovoltaic panel model terminals (in the legend $V_{p v}$ ), showing the action of the PI compensator designed for this purpose.
Figure 8 illustrates the reference voltage (VRef) being disturbed by $\mathrm{P} \& \mathrm{O}$ and the voltage at the PVV photovoltaic panel model terminals (in the legend Vpv). It is noted that the action of the PI compensator maintains the response of this voltage with rapid stabilization around the reference and zero error under steady state, although with some overshoot level and underdamped oscillations.

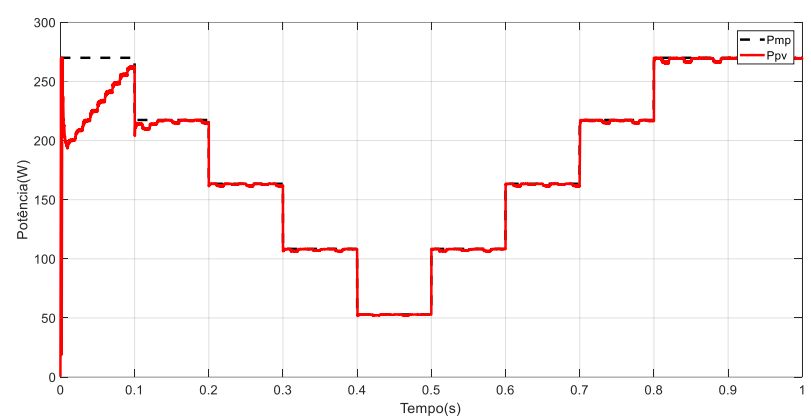

Fig. 6. $\mathrm{P} \& \mathrm{O}$ algorithm following maximum power of the photovoltaic panel model when influenced by different light and temperature profiles.

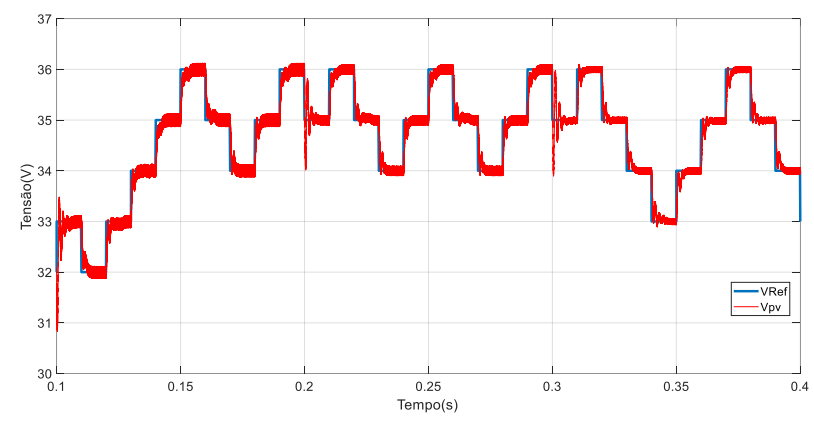

Fig. 7. Reference voltage $\left(V_{R e f}\right)$ being disturbed by $\mathrm{P} \& \mathrm{O}$ and the different voltage levels coinciding with the maximum power points.

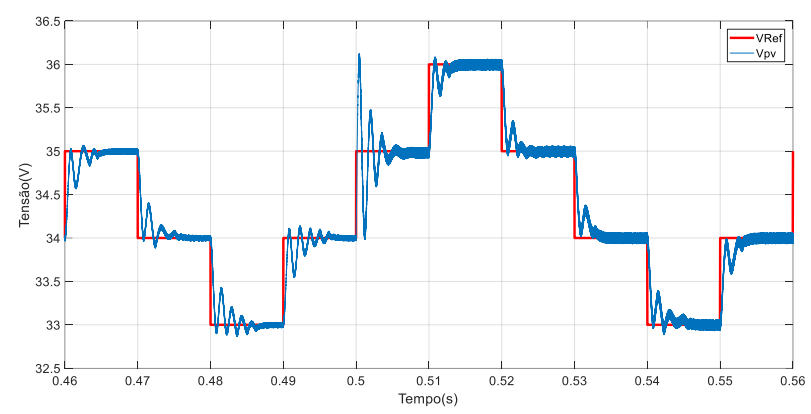

Fig. 8. Reference voltage $\left(\mathrm{V}_{\text {Ref }}\right)$, being disturbed by $\mathrm{P} \& \mathrm{O}$, and the voltage at the terminals of the photovoltaic panel $\left(V_{P V}\right)$ model showing the action of the PI compensator.

\section{B. IMC Controller Results}

Figure 8 presents the result of the simulation of maximum power tracking when the panel model is subjected to different light and temperature profiles. The dashes indicate the power generated (in the subtitle, Panel) and the power (in the subtitle, $P p v$ ) extracted from the panels. In this simulation the $\mathrm{P} \& \mathrm{O}$ algorithm generates the voltage reference $\left(V_{R e f}\right)$ for the IMC controller in the internal control loop of the $V_{P V}$ variable.

Figure 10 shows the reference voltage $\left(V_{R e f}\right)$ being disturbed by $\mathrm{P} \& \mathrm{O}$ and the different levels, showing the action of the IMC controller designed for this purpose.. 
Figure 11 also shows the reference voltage $\left(V_{R e f}\right)$ being disturbed by $\mathrm{P} \& \mathrm{O}$ and the voltage at the terminals of the $V_{P V}$ photovoltaic panel model (in the legend $\mathrm{Vpv}$ ). It can be seen that the action of the IMC controller maintains the response of this voltage with rapid stabilization around the reference, little overshoot and zero error when in steady state.

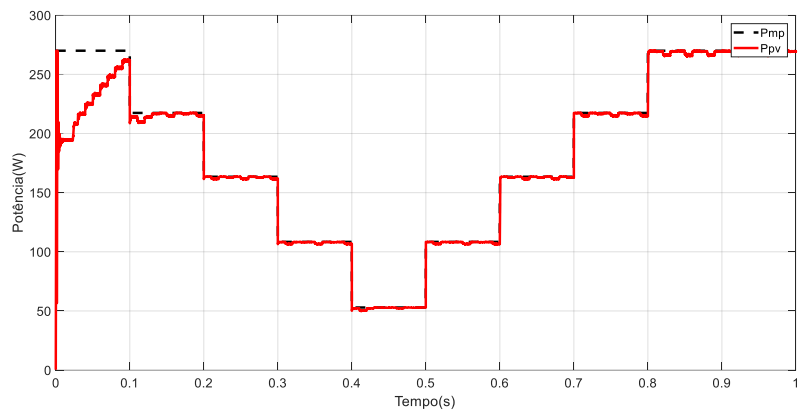

Fig. 9. $\mathrm{P} \& \mathrm{O}$ algorithm following maximum power of the photovoltaic panel model when influenced by different light and temperature profiles.

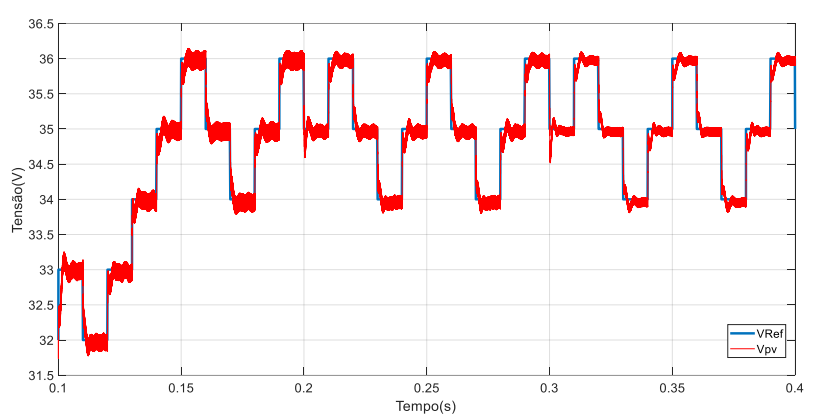

Fig. 10. Reference voltage (VRef) being disturbed by P\&O and the different voltage levels coinciding with the maximum power points.

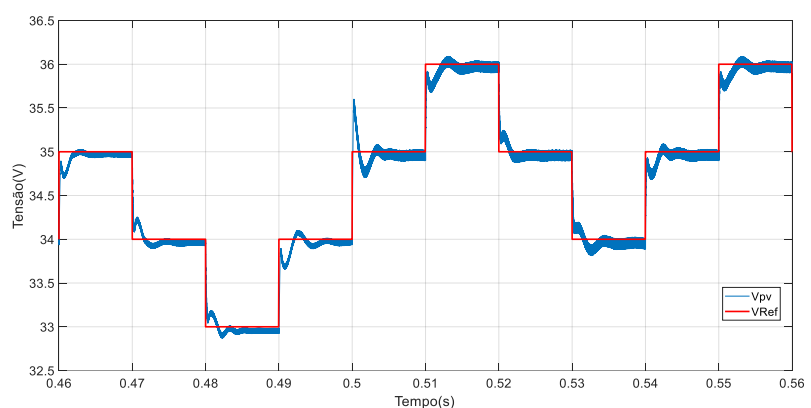

Fig. 11. Reference voltage $\left(V_{R e f}\right)$, being disturbed by $\mathrm{P} \& \mathrm{O}$, and the voltage at the photovoltaic panel $\left(V_{P V}\right)$ model terminals showing the action of the IMC controller..

\section{Conclusions}

The paper presented the mathematical modeling of the ZVS Full-Bridge converter when used in MPPT of photovoltaic systems. For this modeling, the transformer magnetization and dispersion inductances were not considered due to the low dynamic influence on the system when compared to the output filter inductance. For the transformer, only the turns ratio was considered. From the mathematical model, PI and IMC compensators were designed to control the input voltage of the ZVS Full-
Bridge DC-DC converter in the internal loop of the $\mathrm{P} \& \mathrm{O}-\mathrm{MPPT}$ algorithm.

The results showed that the PI compensator maintained the voltage response $(V p v)$ with fast stabilization around the reference and zero error when in steady state. However, it presented overshoot and undamped oscillations much higher than those presented by the action of the IMC controller. In addition, the PI compensator was a little more difficult to tune because it required a compromise relationship between speed of response and saturation in the control action.

In this way, the IMC proved to be easier to tune, since it is necessary to adjust a single parameter $(\varepsilon)$ related to the system cutoff frequency and its closed-loop response speed.

Finally, the results showed that the action of the IMC controller maintained the voltage response $(V p v)$ with fast stabilization around the reference, little overshoot and zero error when in steady state which makes it viable in this kind of application.

\section{Acknowledgement}

The authors thank the Federal Institute of Goiás and ENEL Goiás for their financial support and NUPSE (Energy Systems Research Group) for their support and encouragement.

\section{References}

[1] Sobreira Jr., P. de A., Tofoli, F. L., Braga, H. A. C., Barbosa, P. G., Ferreira, A. A. "Analysis Of MPPT Techniques Applied To The DCM Multiphase Boost Converter For The Mitigation Of Partial Shading In PV Arrays", Power Electronics - Vol. 18, No. 4, September 2013.

[2] Carbone, R., Tomaselli, A., 2011. "Recent advances on AC PV-modules for grid-connected photovoltaic plants", in Proc. IEEE 3rd International Conference on Clean Electrical Power: Renewable Energy Resources Impact, pp. 124- 129.

[3] Lappeenrantaensis,, A. U., 2012. "Performance and scalability of isolated dc-dc converter topologies in low voltage, high current applications". Tese de Doutorado, Lappeenranta University of Technology, Lappeenranta, Finland.

[4] Gazoli, J. R, Villalva, M. G., Brandão, D. I., Marafão, F. P., Ruppert, E, "Microinverter Integrated into Photovoltaic Module for Power Grid Connected Systems Using Resonant Controller" Power Electronics - Vol. 18, No. 2, May 2013.

[5] Bernardo, A., Leonardo, C. B., Martins, M. L. da S., Hey, H. L., Beltrame, R. C., "Modeling of a Full-Voltage ZeroVoltage Switching DC-DC Converter for Photovoltaic Applications," in VII Brazilian Congress of Solar Energy (CBENS), vol. 1, 2018.

[6] Middlebrook, R. D., Cuk, S. J. A., "A General Unified Approach to Modelling Switching-Converter Power Stages", in Proc. of Power Eletronics Specialists Conference, pp. 1-6, 1976.

[7] L. H. S. C. Barreto, "Analysis, design and development of converters for the design of a non-isolated online UPS", Doctoral Thesis, Federal University of Uberlândia - UFU, Uberlândia-MG, Brazil, 2003.

[8] Brosilow, C., Joseph, B., "Techniques of Model-Based Control”, Prentice Hall, 1a Edição, New York, 2002. 